\title{
Studying the relationship between on-farm environmental conditions and local meteorological station data during the summer
}

\author{
D. A. Shock, ${ }^{*}$ S. J. LeBlanc, ${ }^{*}$ K. E. Leslie, ${ }^{*}$ K. Hand,† M. A. Godkin, $\ddagger$ J. B. Coe, ${ }^{*}$ and D. F. Kelton*1 \\ *Department of Population Medicine, University of Guelph, Guelph, Ontario, Canada, N1G 2W1 \\ †Strategic Solutions Group, Puslinch, Ontario, Canada, NOB 2JO \\ ¥Veterinary Science and Policy Group, Ontario Ministry of Agriculture and Food, Fergus, Ontario, Canada, N1G 4Y2
}

\section{ABSTRACT}

High ambient heat and humidity have profound effects on the production, health, profitability, and welfare of dairy cattle. To describe the relationship between summer temperature and relative humidity in the barn and determine the appropriateness of using meteorological station data as a surrogate for on-farm environmental monitoring, a study was conducted on 48 farms in Ontario, Canada, over the summer (May through September) of 2013. Within-barn environmental conditions were recorded using remote data loggers. These values were compared with those of the closest official meteorological station. In addition, farm-level characteristics and heat-abatement strategies were recorded for each farm. Environmental readings within the barn were significantly higher than those of the closest meteorological station; however, this relationship varied greatly by herd. Daily temperature-humidity index (THI) values within the barn tended to be 1 unit higher than those of the closest meteorological station. Numerically, 1.5 times more mean daily THI readings were in excess of 68 (heat stress threshold for lactating dairy cows) in the barn, relative to the closest meteorological station. In addition, tiestalls, herds that were allowed access to pasture, and herds that had no permanent cooling strategy for their cows had the highest mean and maximum daily THI values. Minimum daily THI values were almost 4 units higher for tiestall relative to freestall herds. Overall, due to farm-specific and unpredictable variability in magnitude of environmental differences between on-farm and meteorological station readings, researchers attempting to study the effects of environment on dairy cows should not use readings

Received May 8, 2015.

Accepted November 22, 2015.

${ }^{1}$ Corresponding author: dkelton@uoguelph.ca from meteorological stations because these will often underestimate the level of heat stress to which cows are exposed.

Key words: temperature-humidity index, dairy barn, heat stress

\section{INTRODUCTION}

High ambient heat and humidity have profound effects on the production, health, profitability, and welfare of dairy cattle (Collier et al., 2006). Heat dissipation through conduction, convection, evaporation, and radiation become less effective as temperature and humidity rise, causing an increase in body temperature (West, 2003). To gauge the level of heat stress in cattle, a composite index of heat and humidity, the temperature-humidity index (THI), is a widely used metric (Bohmanova et al., 2007). Historically, it has been accepted that daily average THI values in excess of 72 defined heat stress in dairy cattle (Igono et al., 1992; Armstrong, 1994). However, recent research has found that the negative production effects of heat stress on high-producing dairy cows begin at lower minimum and average daily THI values of 65 and 68 , respectively (Zimbleman et al., 2009). Such conditions of heat stress cause decreases in DMI resulting in lower milk production (West et al., 2003; West, 2003). Heat stress also has negative effects on reproductive performance through altered ova, sperm, and embryo viability, and reduced expression and shorter duration of estrus (Ravagnolo and Misztal, 2002; Pereira et al., 2013). In addition, heat stress may contribute to an increased incidence of metabolic disorders (Duffield et al., 1998; Wheelock et al., 2010) and immune suppression (Elvinger et al., 1992; do Amaral et al., 2011).

The global climate is getting warmer, with a concurrent increased incidence of extreme weather events (an average of weather events over a certain period of time, for example, rainfall over a season, which is itself higher than historic norms; IPCC, 2007). In North America, summer heat waves, understood as acute periods of ex- 
treme warmth, have increased in frequency over the 33 yr of analysis (Smith et al., 2013). Relative to tropical and subtropical regions where environmental conditions remain relatively consistent throughout the year, the summer months in temperate climates represent a period of unique concern, as physiological adaptations to episodic periods of heat stress can take weeks to occur (Collier et al., 2006). Therefore, an increased understanding of the risks associated with heat stress conditions may be relevant for producers in temperate climates.

A variety of factors influence the environmental conditions within a dairy barn. In addition to external climatic conditions, factors such as cow numbers and density, shade, the number and size of fans and sprinkler cooling systems, and barn orientation and position relative to prevailing winds can all influence the environmental conditions inside the barn (Collier et al., 2006; Schueller et al., 2013). A recent German study reported that on-farm measures of temperature and humidity differ significantly from those of the closest official meteorological station, and as such, onfarm measures are likely a better gauge of conditions experienced by cows in a herd (Schueller et al., 2013). That study also reported diversity in the variability between on-farm and meteorological station readings on the 7 study farms, indicating the presence of farmlevel effects contributing to the establishment of barn microclimates. A key limitation of this European study was the use of unconditional correlation analysis, which does not control for repeated measures over time or other potential confounders.

Use of meteorological station data as a surrogate for on-farm measurements would be more convenient and cost effective for producers, farm consultants, and researchers versus installing environmental monitoring equipment in the barn. A previous North American study, set on one farm in Georgia, compared the environmental conditions within the barn with that of the closest meteorological station and concluded that data collected from the meteorological station was an acceptable surrogate for on-farm exposures (Freitas et al., 2006).

The objectives of this study were to first describe the relationship between temperature and relative humidity (RH) in the barn for a convenience sample of 48 dairy farms in southwestern Ontario, Canada, with conditions recorded at the closest official meteorological station, while exploring and controlling for farm-specific environmental factors. In doing so, the appropriateness of using meteorological station data as a surrogate for on-farm environmental monitoring will be determined.

\section{MATERIALS AND METHODS}

\section{Farm Selection and Recruitment}

This study was part of a larger initiative designed to investigate summer-specific herd-level determinants of bulk milk somatic cell count (BMSCC) seasonality in commercial dairy herds in Ontario. Farms were selected based on their historical milk quality and the predicted probability that they would experience a high elevation in their BMSCC during the summer 2013 study period. A list of all dairy farms in Ontario currently selling milk (approximately 4,100 operations) was available for selection of herds. For inclusion in the study, herds must have owned over $30 \mathrm{~kg}$ of butterfat quota, participated in Canwest DHI milk recording services at a frequency of greater than 9 visits per year, had a weighted monthly BMSCC average of between 150,000 and 250,000 cells/mL in January 2013, and been in either the top third or bottom third of projected probabilities for experiencing a high elevation in BMSCC over the summer of 2013 (based on the seasonality model by Shock et al., 2015). A list of 452 herds was generated that fit these criteria. Recruitment letters were mailed, and 3 wk later producers were contacted by telephone to determine their willingness to participate. Ultimately, a convenience sample of 50 herds was recruited for the study, a number limited by funding and logistical constraints.

\section{Farm Visits}

Initial farm visits were conducted during May 2013. Each farm was visited to administer a validated survey (Dufour et al., 2010) designed to assess environmental, housing, biosecurity, and management practices associated with udder health. In addition, one data logger (Hobo U23-01 Pro V2 temperature/RH data logger, Onset Computer Corporation, Bourne, MA) was placed to record ambient temperature and $\mathrm{RH}$ within each barn at half-hour intervals. Data loggers were installed as close to the midpoint (length and width) of the main lactating cow housing area at a position approximately 8 to 10 feet $(2.4$ to $3.0 \mathrm{~m})$ above the floor and equidistant between ventilation devices, if present. The data loggers were collected at the conclusion of the study (October 2013). Data from loggers were downloaded as a comma separated variable (CSV) file for further analysis. Initially, 50 data loggers were installed (1 per farm); however, due to an equipment defect, the number of functioning loggers decreased from 50 in May to 48 in June, 34 in July, 17 in August, and finally 4 in September. 


\section{Environmental Data}

All meteorological stations in Ontario with hourly ambient temperature and $\mathrm{RH}$ readings were considered for use in the current analysis. The geographic distance between each study farm and the closest 2 meteorological stations was assessed using Google Maps Distance Calculator (http://www.daftlogic.com/projects-googlemaps-distance-calculator.htm, last accessed December 23, 2013) by entering the decimal degrees (latitude and longitude) for the study herd and official meteorological station. The meteorological station with the shortest distance to each study herd was used as the station of comparison for that particular farm. Subsequently, daily temperature and $\mathrm{RH}$ data were downloaded for each meteorological station for the period June 1 through September 30, 2013, inclusive, from the Government of Canada's official climate database (http://climate. weather.gc.ca/).

As data logger readings were made at half-hour intervals, they were subsequently converted into hourly readings by taking the mean value for temperature and $\mathrm{RH}$ of 2 readings for each hour in which they were recorded. Data from individual farm logger readings were then merged with corresponding hourly meteorological station data readings to form a complete data set. Values for hourly THIs were calculated using the following formula (NRC, 1971):

$$
\begin{gathered}
\mathrm{THI}=\left(1.8 \times \mathrm{T}^{\circ} \mathrm{C}+32\right)-(0.55-0.0055 \times \mathrm{RH} \%) \\
\times\left(1.8 \times \mathrm{T}^{\circ} \mathrm{C}-26\right),
\end{gathered}
$$

where $\mathrm{T}=$ ambient dry bulb temperature in ${ }^{\circ} \mathrm{C}$, and $\mathrm{RH} \%=$ relative humidity.

\section{Data Analysis}

All data were analyzed using SAS 9.3 (PROC SUMMARY, PROC FREQ; SAS Institute Inc., Cary, NC). Variables were created for the difference in temperature, $\mathrm{RH}$, and THI between the data loggers and the official meteorological station. Subsequently, daily values for mean, maximum temperature, minimum temperature, $\mathrm{RH}$, and THI were calculated for on-farm loggers and meteorological stations. Daily weather data from the official meteorological stations (temperature, RH, THI) were summarized by station. Differences in measurements (on-farm readings minus meteorological station readings) were calculated and subsequently summarized in aggregate and at the individual farm level. Time series plots were made comparing meteorological station THI with that of on-farm logger readings at the study population and individual farm levels to visually assess differences in THI.

Farm characteristics available for analysis were barn type [freestall (FS) versus tiestall (TS)], access to pasture (yes/no), ventilation system (negative pressure, positive pressure, high-volume low-speed fan, and none/temporary), use of natural ventilation in the summer (yes/no), presence of sprinklers (yes/no), number of milking cows, stocking density (number of milking cows/number of stalls), month, meteorological station location, and distance from the closest official meteorological station (in $\mathrm{km}$ ). Herds in the none/temporary class for ventilation had either no functional fans present, or employed temporary fans for ventilation during warmer periods of the summer. The relationships between daily THI outcome variables of interest (mean, minimum, and maximum THI) for official meteorological station and on-farm readings were assessed using Pearson correlation analysis (PROC CORR, SAS Institute Inc., Cary, NC), and subsequently, 3 models were created to explore each outcome.

Initially, univariable linear regression was performed with on-farm THI (daily mean, maximum, and minimum) as the outcome of interest and all available predictor variables. Variables with $P$-values $<0.2$ were retained for inclusion as potential predictors in the final models. Variables were assessed for collinearity using Pearson and Spearman rank-order correlations $(\rho)$. In addition, continuous variables were assessed for linearity by including a quadratic term in the model. In the case of nonlinear relationships (i.e., quadratic term with $P<0.05)$, the quadratic term was included in the model, otherwise the variable remained as linear.

Manual backward elimination was used to build the final multivariable, repeated measures linear model with PROC MIXED in SAS 9.3 (SAS Institute Inc., Cary, NC). Variables with significant $F$-tests $(P<0.05)$ were retained in the model. All biologically plausible interactions were explored. Interactions were retained in the final model at $P<0.05$. The final model used to describe the association between meteorological station maximum daily THI and on-farm maximum daily THI was

$$
\begin{aligned}
& \text { MAXTHI }(\text { farm })=\beta_{0}+\beta_{1} \text { MAXTHI (MS) } \\
+ & \beta_{2} \text { barn type }+\beta_{3} \text { vent-pos }+\beta_{4} \text { vent-tunnel } \\
+ & \beta_{5} \text { pasture }+\beta_{6} \text { THI }(\mathrm{ms}) \times \text { barn type }+\varepsilon, \quad[2]
\end{aligned}
$$

The final model for mean daily THI(ms) and on-farm mean daily THI was 


$$
\begin{aligned}
& \text { MEANTHI }(\text { farm })=\beta_{0}+\beta_{1} \operatorname{MEANTHI}(\mathrm{ms}) \\
& +\beta_{2} \text { barn type }+\beta_{3} \text { vent-pos }+\beta_{4} \text { vent-tunnel } \\
& +\beta_{5} \operatorname{MEANTHI}(\mathrm{ms}) \times \text { barn type }+\varepsilon,
\end{aligned}
$$

The final model for minimum daily THI was

$$
\begin{gathered}
\operatorname{MINTHI}(\text { farm })=\beta_{0+} \beta_{1} \operatorname{MINTHI}(\mathrm{ms}) \\
+\beta_{2} \text { barn type }+\varepsilon
\end{gathered}
$$

where $\beta_{0}=$ the intercept, $\beta_{i}=$ regression coefficients for fixed effects, barn type $=$ either FS or TS housing, $\mathrm{ms}=$ meteorological station, vent-pos $=$ use of positive pressure ventilation system, vent-tunnel $=$ use of negative pressure ventilation system, and $\varepsilon=$ residual error term. Repeated measures were modeled using the autoregressive moving average covariance structure. In all models, the ARMA covariance structure was chosen, as it produced models with the lowest Akaike information criterion compared with all other structures (Dohoo et al., 2009). Residuals for the 3 models were visually assessed for normality and homogeneity of variance across predicted values. Scatterplots of raw residuals against predicted THI values were generated to assess predictive accuracy of all 3 models.

\section{RESULTS}

Initially, a total of 50 farms were enrolled in the study; however, due to equipment malfunction and subsequent failure, the number of farms with environmental data decreased as the study progressed. In total, the number of farms with at least one complete day of readings per month (consisting of 24 hourly temperature and humidity recordings) was 48 in June (34 farms with a complete month), 34 in July (17 complete), 17 in
August (4 complete), and 4 in September (all complete; Table 2). Only complete days were used in the calculation of daily mean, maximum, and minimum climatic data for study herds. The herd characteristics for the 50 herds are presented in Table 1.

In aggregate, temperature and THI were higher in the barn than at meteorological stations. Table 2 includes the differences in mean daily temperature, $\mathrm{RH}$, and THI between on-farm data logger readings and the official meteorological station data from the 11 stations employed in this study. The difference in daily RH between on-farm and official meteorological station readings varied by month, although on aggregate, temperature and $\mathrm{RH}$ were consistently higher in on-farm data logger readings throughout the entire summer period.

Herd-day readings from farm data loggers had a far greater proportion of minimum (2 times more) and mean (1.5 times more) herd-days with THI readings in excess of 65 and 68 than corresponding meteorological station readings. The variability between herds was wide in the magnitude of difference in daily THI readings, specifically in the mean and minimum THI differences. The median daily THI difference (on-farm logger THI minus meteorological station THI) was 1.74 (interquartile range: 0.74-3.19), 3.09 (interquartile range: 1.90-4.69), and 4.64 (interquartile range: $2.67-7.70$ ) for maximum, mean, and minimum THI readings, respectively. Visual representations of herds that have high, medium, and low (based on percentiles) differences between on-farm logger- and meteorological station-generated mean daily THI values are represented in Figure 1.

Results for the final multivariable linear mixed models for mean, maximum and minimum daily THI are presented in Tables 3, 4, and 5, respectively. Controlling for all significant covariates, all models predicted higher on-farm THI readings relative to official meteorological station daily values. Barn type was a significant predic-

Table 1. Herd and barn characteristics, stratified by housing type, for the Ontario dairy farms comprising the study population $(\mathrm{n}=50)$

\begin{tabular}{lrrr}
\hline Item & Freestall & Tiestall & Overall \\
\hline No. of farms & 20 & 30 & 50 \\
Pasture access $^{1}$ Positive pressure ventilation & 3 & 8 & 11 \\
Tunnel $^{2}$ ventilation & 11 & 11 & 22 \\
HVLS $^{3}$ & 2 & 14 & 16 \\
Sprinklers $_{\text {Distance from MS }}^{4}$ & 6 & 0 & 7 \\
No. of milking cows $^{5}$ & 2 & $25.90(7.90-65.53)$ & 2 \\
\hline
\end{tabular}

\footnotetext{
${ }^{1}$ Fans that mechanically push air into the barn, such that the air pressure within the barn is higher than that of outside.

${ }^{2}$ Fans that mechanically pull air into the barn, such that the air pressure within the barn is lower than that of outside.

${ }^{3}$ High-velocity low-speed overhead fans.

${ }^{4}$ Mean (range) distance from meteorological station (MS) in kilometers.

${ }^{5}$ Mean (range) number of cows milking.
} 
Table 2. Population average $(\mathrm{n}=48)$ mean daily temperature, relative humidity $(\mathrm{RH})$, and temperature-humidity index (THI) on farm and at the nearest official meteorological station (MS) for study herds

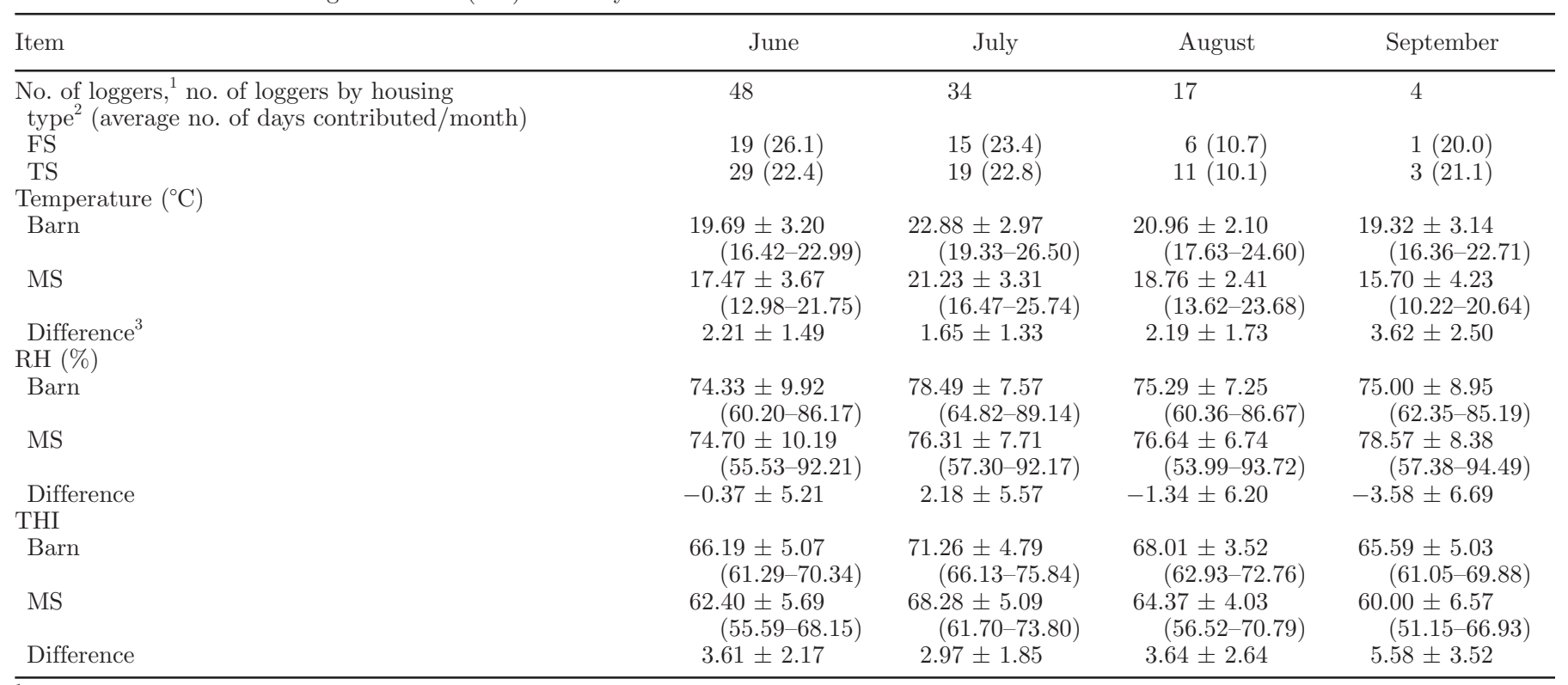

${ }^{1}$ Number of loggers that contributed at least 1 (24 hourly) reading for that specific month.

${ }^{2} \mathrm{FS}=$ no. of freestall barns; TS $=$ no. of tiestall barns.

${ }^{3}$ Difference (barn reading minus meteorological station reading) in average daily herd temperature, $\mathrm{RH}$, and THI.

tor in all models, where FS housing had THI 2.3 units lower in mean THI than TS. Barn type was the only significant predictor for the daily minimum THI model.

\section{DISCUSSION}

The main objective of the study was to decide whether it is appropriate to use the meteorological data from the closest meteorological station to approximate the conditions within the barn on dairy farms in Ontario. On a herd basis, the environmental readings (temperature and THI) obtained using loggers in the cow barn were consistently higher than those of the closest meteorological station, although the magnitude of this difference varied greatly by the day. Even herds in the lowest quartile of difference (logger - meteorological station reading) still had a wide level of variation in daily values (Figure 1c). These results are in agreement with Schüller et al. (2013), who found that temperature, RH, and THI were all consistently higher within the barn microclimate compared with official meteorological stations. Overall, the study by Schüller et al. (2013) noted a mean THI difference of $11.1 \pm 6.5$ throughout the 2 yr of study. During the summer months, the results of Schüller et al. (2013) more closely agree with the current study, with mean differences of 3 to 4 THI units noted. One difference of note was that, for the current study, barn temperature readings were consistently higher than meteorological station readings, whereas this relationship was not consistent for $\mathrm{RH}$ (Table 2); hence, temperature seemed to be the more consistent variable driving the difference in THI, relative to RH. Several notable differences in environmental conditions and study methods and analysis between the 2 papers could have driven the observed differences in results. Notably, Ontario meteorological stations averaged 90 readings with THI over 72 during the 3 summer months, whereas Schüller reported 25 readings in excess of THI 72 over the same period. The Schüller study was also based on relatively fewer ( 7 versus 50$)$ and far larger ( 740 versus $55 \mathrm{cow}$ ) herds, thus potentially limiting broader generalizability and explaining differences in results. Another difference between studies was farm proximity to meteorological stations. The current study averaged $27 \mathrm{~km}$, whereas Schüller et al. (2013) averaged $13 \mathrm{~km}$ between farm and meteorological station. However, in the current study, distance was not a significant predictor of the relationship between meteorological station and farm environmental data. Finally, Schüller et al. (2013) did not account for repeated measures nor were other predictor variables included that could potentially confound the relationship between meteorological station and on-farm environmental readings. The current study has attempted to address some of these concerns. 
a)

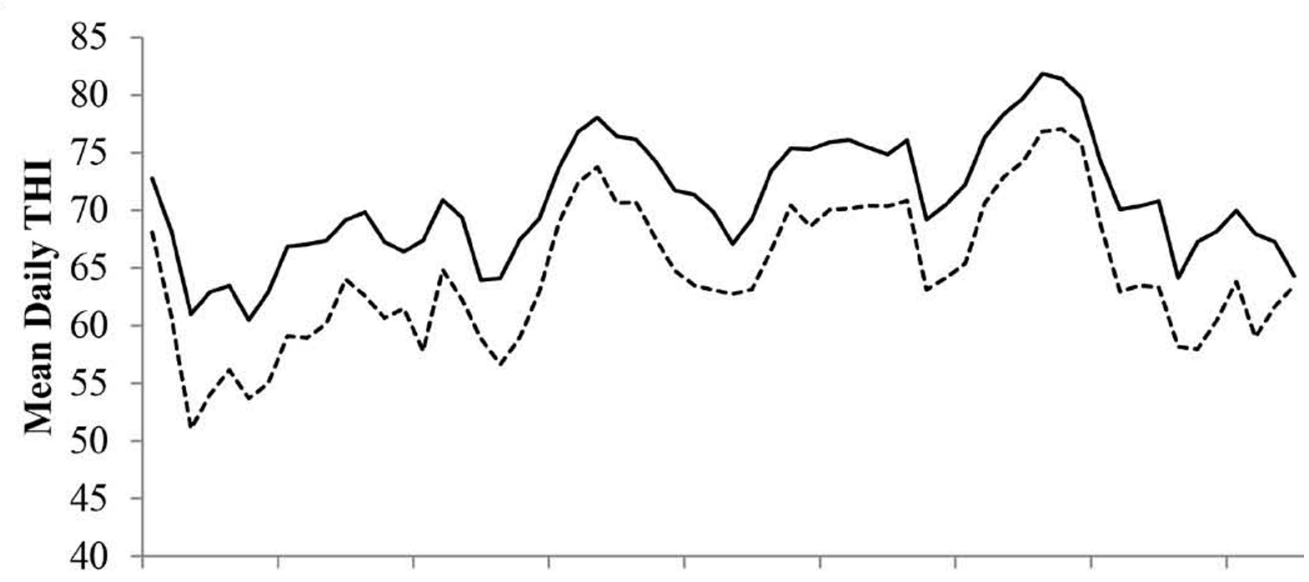

b)

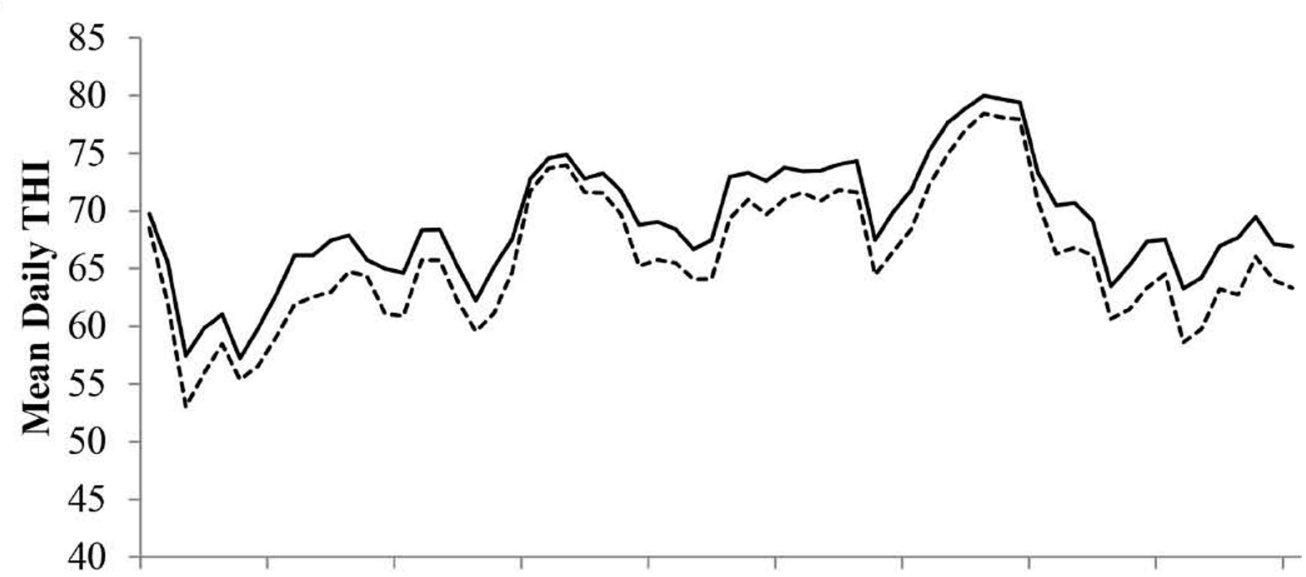

c)

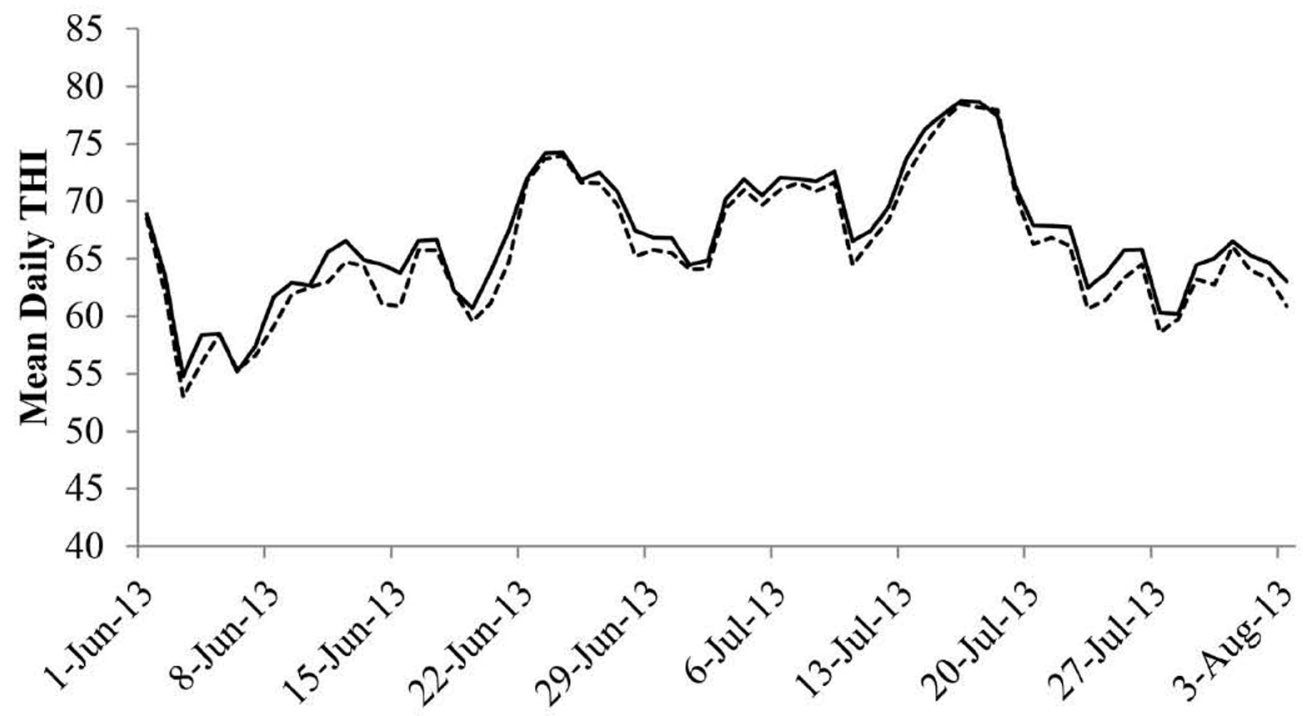

Date

Figures 1. Graphic plots of mean daily temperature-humidity index (THI) readings between on-farm loggers (-) and meteorological station (- - -) readings for a study herd with (a) high-magnitude, (b) medium-magnitude, and (c) low-magnitude differences between on-farm readings and meteorological station readings. 
Table 3. Final multivariable linear mixed regression model assessing the relationship of meteorological station mean daily temperature-humidity index (THI), barn type, pasture access, and mechanical ventilation type on mean daily THI as measured by on-farm data loggers

\begin{tabular}{|c|c|c|c|c|}
\hline Effect & Estimate & $\mathrm{SE}$ & $P$ & $95 \%$ CI \\
\hline Intercept & 15.86 & 0.48 & $<0.0001$ & 14.89 to 16.84 \\
\hline $\mathrm{MS}^{1}$ daily mean THI & 0.81 & 0.01 & $<0.0001$ & 0.80 to 0.82 \\
\hline \multicolumn{5}{|l|}{ Barn type $^{2}$} \\
\hline $\mathrm{FS}$ & -2.27 & 0.29 & $<0.0001$ & -2.85 to -1.69 \\
\hline TS & Referent & & & \\
\hline \multicolumn{5}{|l|}{ Pasture } \\
\hline Yes & 0.53 & 0.29 & 0.08 & -0.08 to 1.13 \\
\hline No & Referent & & & \\
\hline \multicolumn{5}{|l|}{ Ventilation } \\
\hline None $^{3}$ & 1.61 & 0.47 & 0.002 & 0.65 to 2.58 \\
\hline Positive pressure ${ }^{4}$ & 0.49 & 0.31 & 0.12 & -0.13 to 1.11 \\
\hline Negative pressure $^{5}$ & Referent & & & \\
\hline
\end{tabular}

${ }^{1} \mathrm{MS}=$ meteorological station.

${ }^{2} \mathrm{FS}=$ freestall; $\mathrm{TS}=$ tiestall.

${ }^{3}$ Barns had either no means or temporary means of providing mechanical ventilation.

${ }^{4}$ Fans that mechanically push air into the barn, such that the air pressure within the barn is higher than that of outside.

${ }^{5}$ Fans that mechanically pull air into the barn, such that the air pressure within the barn is lower than that of outside.

Table 4. Final multivariable linear mixed regression model assessing the relationship of meteorological station (MS) maximum daily temperature-humidity index (THI), barn type, pasture access, and mechanical ventilation type on maximum daily THI as measured by on-farm data loggers

\begin{tabular}{lcccc}
\hline Effect & Estimate & SE & $P$ & $95 \%$ CI \\
\hline Intercept & 12.19 & 0.51 & $<0.0001$ & 11.15 to 13.24 \\
MS daily maximum THI $^{1}$ & 0.85 & 0.01 & $<0.0001$ & 0.84 to 0.87 \\
$\begin{array}{l}\text { Barn type } \\
\text { FS }\end{array}$ & -1.13 & 0.35 & 0.002 & -1.83 to -0.42 \\
$\quad$ TS & 0 & & & \\
Pasture & 0.88 & 0.36 & 0.02 & 0.15 to 1.62 \\
$\quad$ Yes & Referent & & & \\
No & 2.20 & 0.58 & 0.0005 & 1.01 to 3.37 \\
Ventilation & $\begin{array}{l}0.43 \\
\text { None }\end{array}$ & 0.37 & 0.26 & -0.32 to 1.18 \\
Positive pressure $^{3}$ & Referent & & & \\
Negative pressure $^{4}$ & & & &
\end{tabular}

${ }^{1} \mathrm{FS}=$ freestall; $\mathrm{TS}=$ tiestall

${ }^{2}$ Barns had either no means or temporary means of providing mechanical ventilation.

${ }^{3}$ Fans that mechanically push air into the barn, such that the air pressure within the barn is higher than that of outside.

${ }^{4}$ Fans that mechanically pull air into the barn, such that the air pressure within the barn is lower than that of outside.

Table 5. Final multivariable linear mixed regression model assessing the relationship of meteorological station (MS) minimum daily temperature-humidity index (THI) and barn type on minimum daily THI as measured by on-farm data loggers

\begin{tabular}{lcccc}
\hline Effect & Estimate & SE & $P$ & $95 \%$ CI \\
\hline Intercept & 27.68 & 0.69 & $<0.0001$ & 26.28 to 29.08 \\
MS daily min THI $_{\text {Barn type }}^{1}$ & 0.63 & 0.01 & $<0.0001$ & 0.61 to 0.65 \\
FS & -3.71 & 0.51 & $<0.0001$ & -4.73 to -2.68 \\
TS & Referent & & & \\
\hline
\end{tabular}

${ }^{1} \mathrm{FS}=$ freestall; $\mathrm{TS}=$ tiestall. 
Another study conducted in North America concluded that distant meteorological station environmental data were adequate to use as a surrogate gauge of on-farm conditions (Freitas et al., 2006). A major limitation of that study was that it based its conclusions on observations from a single farm. Using a sample of 48 farms, the present study shows that the high level of variability in agreement between within-barn and meteorological station environmental data, both between barns, and also within the same barn over the summer period.

Inspection of the raw residuals (the difference between the observed and model-predicted value for the individual observation) for each model allows for the evaluation of the predictive usefulness of the model (Dohoo et al., 2009). Although raw residuals for all models were normally distributed and homogeneous in variance across predicted values, a wide degree of variation was still present across the population of herds over time. Twenty percent of residuals for the mean and maximum daily THI models had values of greater than \pm 2 THI units. When considering minimum daily THI, the residuals have a higher degree of variance, with only half having values between \pm 2 THI units. This finding suggests that, although these models have utility in understanding and describing relationships between on-farm and meteorological readings while controlling for potential confounders at the population level, at the level of the individual barn, their variable ability to predict within-barn environmental conditions holds questionable value. A variety of factors could influence the microclimate within the barn environment and explain why they might differ from meteorological station conditions. Some structural considerations that affect the internal environment of a barn and that were not assessed in the current study include barn orientation relative to prevailing winds, presence of foliage surrounding the structure, elevation, barn width, roof slope, and roof type and insulation (Shoshani and Hetzroni, 2013). Other factors that contribute to internal barn microclimate are stocking density, air velocity and exchange through mechanical ventilation systems, presence of sprinklers, and shade (Stowell et al., 2001; Kadzere et al., 2002; Wagner-Storch and Palmer, 2002; Stowell et al., 2003). Theoretically, to increase the usefulness of a predictive model, future studies should evaluate these factors in an attempt to improve the accuracy of model predictions, though practical constraints might limit this approach. Alternatively, building-specific environmental monitoring is likely more appropriate to describe environmental conditions within a specific barn.

In the current study, housing type was found to play a significant role in determining daily THI values within the barn environment. Peer-reviewed literature that documents the influence of housing type on withinbarn conditions is lacking. One study found that cows housed in loose housing systems had significantly lower temperatures relative to FS-housed cows (Shoshani and Hetzroni, 2013). The authors attributed these differences to higher animal densities seen in FS housing, along with additional structural elements (i.e., stall dividers and cement walls) that may act to obstruct air flow and increase temperature and humidity within the barn. Extrapolating this hypothesis to the present study, TS barns typically have higher cow densities per square foot of overall floor space than FS milking the same number of cows. Tiestalls do not have the additional floor space requirements associated with cow movement, nor do they typically employ large drivethrough feed delivery systems that are present in FS facilities. Tiestall facilities tend to be older than FS (Simensen et al., 2010), typically having lower ceilings with solid external walls, leading to a restriction in natural ventilation and resulting in higher temperature and humidity values in the barn. Only one TS facility in the current study was constructed within the last 10 yr, the remainder being predominantly older bank-barn style facilities.

Pasture access was also significantly associated with an increase in mean and maximal daily THI values. One explanation is producers allowing their cows access to pasture likely did not have their ventilation systems functioning when the cows were outside of the barn, potentially contributing to higher THI conditions within the barn. All producers in the study noted that they would keep their cattle indoors on exceedingly warm days in the summer, although none were able to describe explicit criteria upon which this decision was made. It is possible that some herds that pasture their cows did so on several warm days throughout the summer, potentially leading to more extreme daily environmental conditions measured within these facilities. This could affect the welfare and performance of the cows because when THI was in excess of 72 , cows housed exclusively on pasture with access to shade had increased levels of systemic cortisol levels relative to cows housed exclusively indoors (Higashiyama et al., 2013). Further, when given the choice, cows will elect to remain indoors during periods where daily THI is high, predominantly choosing to access pasture at night when environmental conditions are milder (Falk et al., 2012). One must also consider reverse causation in this relationship. Specifically, producers that had older/ warmer barns might have been more likely to allow cows access to pasture, rationalizing that conditions are cooler at pasture relative to the barn. Producers that 
pasture their cows during the summer period should consider potential deleterious health and welfare effects of allowing cow access to pasture during periods of extreme environmental conditions.

Presence of ventilation, either positive or negative pressure systems, played a significant role in decreasing the environmental extremes within the barn. Despite this intervention, environmental conditions within the barn were often still warmer relative to ambient conditions. A focus on heat stress abatement strategies within the barn, such as air movement with fans, soaking the cow's body, high-pressure mist to cool the air in the cows' environment, and facilities designed to minimize the transfer of solar radiation have all been proven to minimize the effects of heat on body temperature and thereby improve DMI, milk production, reproduction, and immunological function in cows during the summer period (Collier et al., 2006; Smith et al., 2006; do Amaral et al., 2011; Calegari et al., 2012).

Interestingly, both distance from, and location of, the meteorological station had no effect on the relationship between meteorological station environmental readings and those of on-farm data loggers. Herds that were closer to their respective meteorological station actually had numerically more THI hourly readings greater than 68 (relative to the meteorological station) than did herds that were farther away from their respective meteorological station; however, this difference was not statistically significant. Although the weather conditions within Ontario vary by region, this variance might not be profound enough to enable the statistical detection of a difference in logger THI when distance or meteorological station is introduced into a multivariable model. Also, herd size and stocking density were not identified as significant predictors of on-farm THI. As external temperature and humidity increase, compensatory homeostatic mechanisms begin to take over, whereby the cow's physiologic system attempts to dissipate heat gain through conduction, convection, radiation, and evaporation (primarily through increased respiratory rate; Kadzere et al., 2002). Future studies should evaluate barn-specific factors (i.e., herd size, stocking density) on indicators of cow-level heat stress (body temperature, respiratory rate). It stands to reason that an increased concentration of cows attempting to increase heat loss would increase the temperature inside the barn environment; hence, herds with higher stocking densities would likely have higher THI values.

Only 48 of 50 herds had adequate records for analysis; therefore, the study was limited in degrees of freedom available for construction of larger multivariable models. Although the HOBO data loggers were designed to withstand harsh environmental conditions, they experienced a profound rate of malfunctioning in the current study, due solely to a manufacturing defect. The insulating rubber bracket attaching the battery to the units was defective, causing logger batteries to discharge at a precipitous rate and leading to premature failure in 46 out of 50 units by the end of the study. Replacement parts were not available until the conclusion of the study, leading to an incomplete data set for analysis. Low herd numbers, magnified by equipment malfunction, could have limited the power to detect statistical differences in THI for some predictors classified as nonsignificant. Onset HOBO data loggers (Onset Computer Corporation, Bourne, MA) have been used successfully to accurately measure both animal activity and environmental conditions numerous studies (Wagner-Storch and Palmer, 2002; Bonk et al., 2013; Dikmen et al., 2014; Sepúlveda-Varas et al., 2014; Ortiz et al., 2015); however, given their poor reliability in the current study, their utility is questionable in medium-term research.

Another potential limitation of the study was the reliance on a single temperature/humidity logger per farm. Again, Schüller et al. (2013) found significant variability in environmental conditions within barns. The current study attempted to minimize variability that barn-specific microclimates would have caused through measuring only the milking cow environment by placing loggers at one specific location in each barn. The results of both studies show very similar trends when comparing on-farm environmental readings with those of meteorological stations. Therefore, though including several loggers over a variety of locations on the same farm would likely have provided a deeper understanding of the microclimates present, installing a single logger per farm was still consistent with the trend in results from previous research. Several farm-level factors, such as age of the barn structure, cow density per square foot, bedding material/management, airflow-blocking physical structures, and performance characteristics of fans employed, were not accounted for in the current study that played a role in the predictive ability of the model on an individual herd basis.

Additional studies focused on studying the relationship between meteorological station and on-farm environmental readings should seek to include a larger number of herds, along with a more detailed data collection procedure, focusing on quantification of specific ventilation strategies, barn construction and orientation, bedding material/management, and presence of prevailing winds. With a better understanding of this relationship, a model could be constructed that would 
conceivably allow a more accurate prediction of onfarm environmental conditions from readings taken at meteorological stations.

\section{CONCLUSIONS}

Environmental conditions measured inside dairy facilities exhibit a wide degree of variability when compared with measurements made at the closest meteorological station. Tiestall housing, provision of pasture access, and use of fewer ventilation interventions were found to contribute to higher daily mean and maximum daily THI readings within the barn. After controlling for these factors, THI within the barn environment remained higher than ambient conditions recorded at meteorological stations. When considering the wide and unpredictable variability in the difference in magnitude of environmental readings, coupled with the wide variation in the number of hours in excess of heat stress-level THI readings throughout the summer between barn and meteorological station, using meteorological station environmental data is not a good proxy for on-farm conditions. Environmental readings should be made within the barn to ensure accuracy when measuring environmental exposure levels.

\section{ACKNOWLEDGMENTS}

The authors thank the Dairy Farmers of Ontario (Mississauga, Ontario, Canada) for providing project funding and access to historic milk regulatory data. In addition, special thanks are reserved for summer students Melissa Wagner, John Wynands, and Gillian Marson who provided logistical and technical support through the conduct of the study. Thanks also to William Sears (Department of Population Medicine, University of Guelph) who provided additional statistical expertise throughout the analysis.

\section{REFERENCES}

Armstrong, D. V. 1994. Heat-stress interaction with shade and cooling. J. Dairy Sci. 77:2044-2050.

Bohmanova, J., I. Misztal, and J. B. Cole. 2007. Temperature-humidity indices as indicators of milk production losses due to heat stress. J. Dairy Sci. 90:1947-1956.

Bonk, S., O. Burfeind, V. S. Suthar, and W. Heuwieser. 2013. Technical note: Evaluation of data loggers for measuring lying behavior in dairy calves. J. Dairy Sci. 96:3265-3271.

Calegari, F., L. Calamari, and E. Frazzi. 2012. Misting and fan cooling of the rest area in a dairy barn. Int. J. Biometeorol. 56:287-295.

Collier, R. J., G. Dahl, and M. VanBaale. 2006. Major advances associated with environmental effects on dairy cattle. J. Dairy Sci. 89:1244-1253.

Dikmen, S., F. A. Khan, H. J. Huson, T. S. Sonstegard, J. I. Moss, G. E. Dahl, and P. J. Hansen. 2014. The SLICK hair locus derived from Senepol cattle confers thermotolerance to intensively managed lactating Holstein cows. J. Dairy Sci. 97:5508-5520. do Amaral, B. C., E. E. Connor, S. Tao, M. J. Hayen, J. W. Bubolz, and G. E. Dahl. 2011. Heat stress abatement during the dry period influences metabolic gene expression and improves immune status in the transition period of dairy cows. J. Dairy Sci. 94:86-96.

Dohoo, I. R., S. W. Martin, and H. Stryhn. 2009. Veterinary Epidemiologic Research. 2nd ed. VER Inc., Charlottetown, Prince Edward Island, Canada.

Duffield, T. F., D. Sandals, K. Leslie, K. Lissemore, B. McBride, J. Lumsden, P. Dick, and R. Bagg. 1998. Effect of prepartum administration of monensin in a controlled-release capsule on postpartum energy indicators in lactating dairy cows. J. Dairy Sci. 81:2354-2361.

Dufour, S., K. Reyher, J. Roy, D. T. Scholl, I. R. Dohoo, H. W. Barkema, L. DesCoteaux, and T. J. DeVries. 2010. Development and validation of a bilingual questionnaire for measuring udder health related management practices on dairy farms. Prev. Vet. Med. 95:74-85.

Elvinger, F., R. P. Natzke, and P. J. Hansen. 1992. Interactions of heat stress and bovine somatotropin affecting physiology and immunology of lactating cows. J. Dairy Sci. 75:449-462.

Falk, A. C., D. M. Weary, C. Winckler, and M. A. G. von Keyserlingk. 2012. Preference for pasture versus freestall housing by dairy cattle when stall availability indoors is reduced. J. Dairy Sci. 95:64096415.

Freitas, M. S., I. Misztal, J. Bohmanova, and J. West. 2006. Utility of on- and off-farm weather records for studies in genetics of heat tolerance. Livest. Sci. 105:223-228

Higashiyama, Y., M. Higashiyama, K. Ikeda, T. Komatsu, and M. Fukasawa. 2013. Welfare of lactating Holstein cows under outdoor grazing and indoor housing in relation to temperature and humidity in summer in Japan. Livest. Sci. 155:86-91.

Igono, M. O., G. Bjotvedt, and H. T. Sanfordcrane. 1992. Environmental profile and critical-temperature effects on milk-production of Holstein cows in desert climate. Int. J. Biometeorol. 36:77-87.

IPCC. 2007. Climate change 2007: The physical science basis. in Contribution of Working Group I to the Fourth Assessment Report of the Intergovernmental Panel on Climate Change. S. Solomon, D. Qin, M. Manning, Z. Chen, M. Marquis, K. B. Averyt, M. Tignor, and H. L. Miller, ed. Cambridge University Press, Cambridge, United Kingdom, and New York, NY.

Kadzere, C., M. Murphy, N. Silanikove, and E. Maltz. 2002. Heat stress in lactating dairy cows: A review. Livest. Prod. Sci. 77:59-91.

NRC. 1971. A Guide to Environmental Research on Animals. Natl. Acad. Sci., Washington, DC.

Ortiz, X. A., J. F. Smith, F. Rojano, C. Y. Choi, J. Bruer, T. Steele, N. Schuring, J. Allen, and R. J. Collier. 2015. Evaluation of conductive cooling of lactating dairy cows under controlled environmental conditions. J. Dairy Sci. 98:1759-1771.

Pereira, M. H. C., A. D. P. Rodrigues, T. Martins, W. V. C. Oliveira, P. S. A. Silveira, M. C. Wiltbank, and J. L. M. Vasconcelos. 2013. Timed artificial insemination programs during the summer in lactating dairy cows: Comparison of the 5-d Cosynch protocol with an estrogen/progesterone-based protocol. J. Dairy Sci. 96:6904-6914.

Ravagnolo, O., and I. Misztal. 2002. Effect of heat stress on non-return rate in Holsteins: Fixed-model analyses. J. Dairy Sci. 85:31013106 .

Schüller, L. K., O. Burfeind, and W. Heuwieser. 2013. Short communication: Comparison of ambient temperature, relative humidity, and temperature-humidity index between on-farm measurements and official meteorological data. J. Dairy Sci. 96:7731-7738.

Sepúlveda-Varas, P., D. M. Weary, and M. A. von Keyserlingk. 2014 Lying behavior and postpartum health status in grazing dairy cows. J. Dairy Sci. 97:6334-6343.

Shock, D. A., S. J. LeBlanc, K. E. Leslie, K. Hand, M. A. Godkin, J. B. Coe, and D. F. Kelton. 2015. Exploring the characteristics and dynamics of Ontario dairy herds experiencing elevations in bulk milk somatic cell count during the summer. J. Dairy Sci. 98:3741-3753

Shoshani, E., and A. Hetzroni. 2013. Optimal barn characteristics for high-yielding Holstein cows as derived by a new heat-stress model. Animal 7:176-182. 
Simensen, E., O. Osteras, K. E. Boe, C. Kielland, L. E. Ruud, and G. Naess. 2010. Housing system and herd size interactions in Norwegian dairy herds; associations with performance and disease incidence. Acta Vet. Scand. 52:14.

Smith, T. R., A. Chapa, S. Willard, C. Herndon Jr., R. J. Williams, J. Crouch, T. Riley, and D. Pogue. 2006. Evaporative tunnel cooling of dairy cows in the southeast. II: Impact on lactation performance. J. Dairy Sci. 89:3915-3923.

Smith, T. T., B. F. Zaitchik, and J. M. Gohlke. 2013. Heat waves in the United States: Definitions, patterns and trends. Clim. Change 118:811-825.

Stowell, R., C. Gooch, and S. Inglis. 2001. Performance of tunnel ventilation for free stall dairy facilities as compared to natural ventilation with supplemental cooling fans. Pages 29-40 in Livestock Environment, Proc. 6th Int. Symp., Louisville, KY. American Society of Agricultural Engineers, St. Joseph, MI.

Stowell, R. R., C. A. Gooch, and W. G. Bickert. 2003. Design parameters for hot weather ventilation of dairy housing: A critical review. Pages 218-226 in 5th Int. Dairy Housing Conf., Fort Worth, TX. American Society of Agricultural Engineers, St. Joseph, MI.
Wagner-Storch, A. M., and R. Palmer. 2002. Day and night seasonal temperature differences for a naturally ventilated free stall barn with different stocking densities. J. Dairy Sci. 85:3534-3538.

West, J. W. 2003. Effects of heat-stress on production in dairy cattle. J. Dairy Sci. 86:2131-2144.

West, J. W., B. Mullinix, and J. Bernard. 2003. Effects of hot, humid weather on milk temperature, dry matter intake, and milk yield of lactating dairy cows. J. Dairy Sci. 86:232-242.

Wheelock, J. B., R. P. Rhoads, M. J. VanBaale, S. R. Sanders, and L. H. Baumgard. 2010. Effects of heat stress on energetic metabolism in lactating Holstein cows. J. Dairy Sci. 93:644-655.

Zimbleman, R. B., R. P. Rhoads, M. L. Rhoads, G. C. Duff, L. H. Baumgard, and R. J. Collier. 2009. A re-evaluation of the impact of temperature humidity index (THI) and black globe humidity index (BGHI) on milk production in high producing dairy cows. Pages 158-168 in 24th Annu. Southwest Nutrition Management Conf., Temple, AZ. University of Arizona, Tucson. 